\title{
Effect of glucagon on left ventricular performance in aortic stenosis
}

\author{
John Hamer, Derek Gibson, ${ }^{1}$ and John Coltart ${ }^{2}$ \\ From the Cardiac Department, St. Bartholomew's Hospital, London
}

The effect of intravenous glucagon ( 2 or $3 \mathrm{mg}$ ) was studied at cardiac catheterization in 3 patients with severe aortic stenosis, using a thermodilution technique to measure left ventricular volume. There was a striking rise in cardiac output (from 4.4 to $6.3 \mathrm{l}$./min on average) with only a moderate increase in heart rate. Left ventricular end-diastolic pressure rose considerably and there was a conspicuous increase in left ventricular volume. However, mean circumferential shortening rate, an index of contractility, was little affected. As left ventricular systolic pressure rose, there was a considerable increase in wall force, possibly due to the FrankStarling effect in the dilated left ventricle.

These findings suggest that glucagon does not have a noticeable effect on contractility in the failing myocardium. Other evidence has shown a large increase in splanchnic blood flow after glucagon, and it seems likely that the cardiac changes observed are largely secondary to the increase in venous return. The therapeutic value of this response in cardiac disease is questionable.

The pancreatic hormone, glucagon, has been shown to increase myocardial contractility in animals by a mechanism independent of the action of catecholamines. The effect persists in the presence of betasympathetic blockade and is not associated with the production of ventricular arrhythmias (Glick et al., 1968; Katz, Hinds, and Mills, 1969). These findings have led to the use of glucagon in man in cardiogenic shock (Mahon, Morch, and Klein, I968), after valve replacement (Parmley, Matloff, and Sonnenblick, 1969), or in congestive cardiac failure (Brogan, Kozonos, and Overy, 1969). In addition to its cardiac action, glucagon is a potent peripheral vasodilator (Glick et al., 1968; Katz and Mills, 1971), and this effect may play a part in the response to glucagon treatment in patients with severe heart disease.

The cardiac effects of glucagon are probably mediated in the same way as the action of catecholamines, by stimulation of myocardial adenylcyclase leading to an increased formation of cyclic adenosine monophosphate. On this basis an increase in the velocity of myocardial contraction might be expected. We have investigated the effects of intra-

Received 1o August 1972.

1 Present address: The Brompton Hospital, London S.W.3.

2 Present address: The Cardiovascular Research Institute, San Francisco, U.S.A. venous glucagon in patients with severe aortic stenosis, as it has previously been shown that the converse, a reduction in the velocity of contraction, can be demonstrated in this condition when the actions of catecholamines are blocked by giving intravenous propranolol (Hamer and Fleming, 1967, 1969). Though an impressive rise in cardiac output was produced by glucagon, we were unable to show convincing evidence of an increase in the velocity of myocardial contraction.

\section{Methods}

Three patients with severe aortic stenosis who were being assessed for aortic valve replacement because of symptoms of left ventricular failure were studied, with their informed consent, during diagnostic cardiac catheterization. In two of the patients there was slight aortic regurgitation in addition to the stenosis. The investigation was performed in the fasting state without premedication, and pressures were referred to a baseline at the mid-chest. Catheterization of the right heart and measurement of the cardiac output by the Fick principle was carried out via the right saphenous vein. A Brockenbrough catheter was then inserted and the left ventricle entered by transseptal puncture. A No. 5 Teflon Gensini catheter was passed to the abdominal aorta by percutaneous puncture of the right femoral artery, and cardiac output was measured by the indicator dilution technique using a Gilford cuvette and indocyanine green. The indicator dilution curve was calibrated by the dynamic 


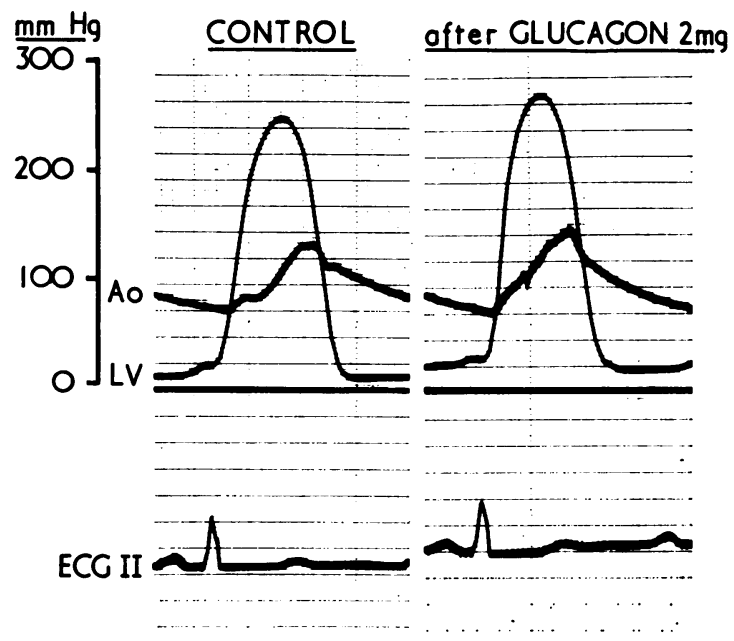

FIG. I Example of the effect of glucagon on left ventricular and aortic pressures (Case 3).

method (Shinebourne, Fleming, and Hamer, 1967). The catheter was then advanced to the ascending aorta about $\mathrm{I} \mathrm{cm}$ above the aortic valve. The aortic pressure gradient and left ventricular diastolic pressure were measured with a P23G Statham strain gauge and a direct-writing recorder at a paper speed of $80 \mathrm{~mm} / \mathrm{sec}$ (Fig. I). A nickelchromium to nickel-aluminium thermocouple with a time constant of $0.1 \mathrm{sec}$, was inserted into the aortic catheter until the wire just protruded from the tip. Multiple thermodilution curves were recorded on a photographic recorder after the injection of 5 to $10 \mathrm{ml}$ ice-cold saline into the left ventricle. Injections were repeated as soon as the curve reached the baseline. The patient was then given 2 or $3 \mathrm{mg}$ ( $35 \mu \mathrm{g} / \mathrm{kg}$ body weight) glucagon in $100 \mathrm{ml}$ saline over ro minutes into a left forearm vein. After a further Io minutes the thermodilution curves were repeated: the thermocouple was then removed from the catheter and the pressure measurements repeated, and finally the catheter was withdrawn to the abdominal aorta and the cardiac output measured again by the indicator dilution method. On each occasion the thermodilution curves and the measurements of cardiac output by indicator dilution were performed within a period of Io minutes without evident change in the state of the patient.

The ratio between the steps of the thermodilution curve (r) was measured from the fourth beat after the appearance of the indicator until accurate measurement became difficult. If an ectopic beat occurred no measurements were made until there had been two subsequent normal beats. From 3 to 5 curves were obtained before and after glucagon in each subject, giving from II to 20 ratios for measurement on each occasion. The average of these values was used to calculate the left ventricular end-diastolic volume. The thermodilution ratio $(r)$ is a measure of the degree of emptying of the ventricle, and the end-diastolic volume is obtained by dividing the stroke volume by the fraction $\mathrm{I}-\mathrm{r}$ :

$$
\begin{aligned}
& \mathbf{r}=\frac{\mathrm{ESV}}{\mathrm{EDV}}=\frac{\mathrm{EDV}-\mathrm{SV}}{\mathrm{EDV}}=\mathrm{I}-\frac{\mathrm{SV}}{\mathrm{EDV}}, \\
& \frac{\mathrm{SV}}{\mathrm{EDV}}=\mathrm{r}-\mathrm{r} \text {, } \\
& \text { and } \quad \mathrm{EDV}=\frac{\mathrm{SV}}{\mathrm{I}-\mathrm{r}} \text {, }
\end{aligned}
$$

where $\mathrm{ESV}=$ end-systolic volume, $\mathrm{EDV}=$ end-diastolic volume, and $\mathrm{SV}=$ stroke volume.

Average values for left ventricular wall force and velocity were calculated from the end-systolic and enddiastolic volume measurements, assuming a thin-walled spherical chamber with a constant rate of ejection throughout systole. Mean systolic force was calculated as the product of left ventricular mean systolic pressure ( $\mathrm{mmHg}$ ) and mean cross-sectional area $\left(\mathrm{cm}^{2}\right)\left(\mathrm{F}=\mathbf{P} \pi \mathbf{r}^{2}\right)$, and force-time per minute, by analogy with the pressuretime per minute of Sarnoff and his colleagues (1958), as the product of mean systolic force $\left(\mathrm{mmHg} \times \mathrm{cm}^{2}\right)$, the duration of ventricular systole (sec), and the heart rate (per $\mathrm{min}$ ). Mean circumferential shortening rate $(\mathrm{cm} / \mathrm{sec}$ ) was calculated from the ejection time and the difference between end-systolic and end-diastolic circumference.

\section{Results}

The investigation confirmed the presence of severe aortic stenosis in each patient (peak aortic valve gradient 90 to $130 \mathrm{mmHg}$ ), and the left ventricular end-diastolic pressures were considerably raised. Intravenous glucagon by slow injection in a dose of $35 \mu \mathrm{g} / \mathrm{kg}$ body weight produced some nausea in two patients (Cases I and 3). Blood glucose was measured in two patients and rose by an average of 34 $\mathrm{mg} / 100 \mathrm{ml}$; there was no consistent change in serum potassium level (Table $I$ ).

The haemodynamic changes followed a similar trend in each case (Table 2) and the results described are average values. The heart rate increased

\begin{tabular}{|c|c|c|c|}
\hline Case No. & $I$ & 2 & 3 \\
\hline Age (yr) & 42 & 60 & 46 \\
\hline Sex & $M$ & $\mathbf{F}$ & M \\
\hline Weight (kg) & 80 & 55 & $8 I$ \\
\hline Body surface area $\left(\mathrm{m}^{2}\right)$ & I.95 & $\mathbf{I} \cdot 55$ & $2 \cdot 00$ \\
\hline Peak aortic valve gradient (mmHg) & 90 & Iro & 130 \\
\hline Aortic incompetence (grade o to 4 ) & I & 0 & I \\
\hline Glucagon dose (mg) & 3 & 2 & 3 \\
\hline 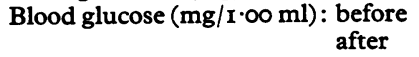 & $\begin{array}{l}57 \\
80\end{array}$ & - & $\begin{array}{r}83 \\
128\end{array}$ \\
\hline $\begin{array}{c}\text { Serum K (mEq/1.): before } \\
\text { after }\end{array}$ & $\begin{array}{l}4 \cdot 6 \\
3 \cdot 6\end{array}$ & - & $\begin{array}{l}3 \cdot 6 \\
3 \cdot 8\end{array}$ \\
\hline
\end{tabular}
from $8 \mathrm{I}$ to $90 /$ minute, and the aortic pressure changed from $130 / 80$ to $150 / 75 \mathrm{mmHg}$, i.e. an in-

\section{TABLE I Clinical features of the 3 patients}


TABLE 2 Haemodynamic effects of glucagon

\begin{tabular}{lccllll}
\hline Heart rate (per min) & & \multicolumn{3}{l}{$\begin{array}{l}\text { Left ventricular pressure } \\
\text { (mmHg) }\end{array}$} \\
\cline { 5 - 7 } \cline { 5 - 7 } & Before & After & & $\begin{array}{l}\text { Peak } \\
\text { systolic }\end{array}$ & Before & After \\
& & & & & \\
\hline Case I & 86 & 104 & & Case I & 210 & 225 \\
Case 2 & 68 & 75 & & Case 2 & 260 & 320 \\
Case 3 & 88 & 90 & & Case 3 & 255 & 270 \\
\hline Mean & 81 & 90 & & Mean & 240 & 270 \\
\hline
\end{tabular}

Cardiac output (l./min)

\begin{tabular}{lrrrrrr}
\hline & Before & After & & ' $a$ ' wave & Before & After \\
\hline Case I & 3.6 & 5.9 & & Case I & 18 & 27 \\
Case 2 & 4.1 & 6.3 & & Case 2 & 33 & 36 \\
Case 3 & 5.4 & 6.7 & & Case 3 & 30 & 38 \\
\hline Mean & 4.4 & 6.3 & & Mean & 27 & 34
\end{tabular}

Stroke volume $(\mathrm{ml})$

\begin{tabular}{lcccllll}
\hline & Before & After & & $\begin{array}{l}\text { End- } \\
\text { diastolic }\left(z^{\prime}\right)\end{array}$ & Before & After \\
\hline Case I & 42 & 57 & & Case I & 14 & 24 \\
Case 2 & 60 & 84 & & Case 2 & 32 & 37 \\
Case 3 & 61 & 75 & & Case 3 & 27 & 33 \\
\hline Mean & 54 & 72 & & Mean & 24 & 31
\end{tabular}

Ejection time (msec)

\begin{tabular}{|c|c|c|c|c|c|}
\hline & Before & After & Systolic & Before & After \\
\hline $\begin{array}{l}\text { Case I } \\
\text { Case } 2 \\
\text { Case } 3\end{array}$ & $\begin{array}{l}340 \\
380 \\
320\end{array}$ & $\begin{array}{l}320 \\
380 \\
340\end{array}$ & $\begin{array}{l}\text { Case I } \\
\text { Case } 2 \\
\text { Case } 3\end{array}$ & $\begin{array}{l}120 \\
150 \\
125\end{array}$ & $\begin{array}{l}140 \\
180 \\
125\end{array}$ \\
\hline Mean & 350 & 350 & Mean & 130 & 150 \\
\hline
\end{tabular}

Total systolic time (msec)

\begin{tabular}{lccccccc}
\hline & Before & After & & & Diastolic & Before & After \\
\hline Case I & 380 & 430 & & Case I & 75 & 80 \\
Case 2 & 420 & 430 & & Case 2 & 100 & 80 \\
Case 3 & 420 & 420 & & Case 3 & 70 & 70 \\
\hline Mean & 410 & 430 & & Mean & 80 & 75
\end{tabular}

crease in pulse pressure with little change in the mean value. The peak left ventricular systolic pressure rose from 240 to $270 \mathrm{mmHg}$, and the left ventricular end-diastolic pressure after the a wave $\left(z^{\prime}\right)$ rose from 24 to $31 \mathrm{mmHg}$, with a concomitant increase in the height of the a wave (Fig. 2). There was

TABLE 3 Effects of glucagon on volume, force, and velocity measurements

\begin{tabular}{|c|c|c|c|c|c|}
\hline \multicolumn{3}{|c|}{ Thermodilution ratio $(r)$} & \multicolumn{3}{|c|}{$\begin{array}{l}\text { Force-time per minute } \\
\left(\mathrm{mmHg} \mathrm{cm} \mathrm{cm}^{2} \mathrm{sec} / \mathrm{min} \times \mathrm{IO}^{-3}\right)\end{array}$} \\
\hline & Before & After & & Before & After \\
\hline $\begin{array}{l}\text { Case I } \\
\text { Case ? }\end{array}$ & $\begin{array}{l}0.63 \\
0.68\end{array}$ & $\begin{array}{l}0.73 \\
0.72\end{array}$ & $\begin{array}{l}\text { Case I } \\
\text { Case ? }\end{array}$ & $\begin{array}{r}75 \\
80\end{array}$ & $\begin{array}{l}175 \\
335\end{array}$ \\
\hline $\begin{array}{l}\text { Case } 2 \\
\text { Case } 3\end{array}$ & $\begin{array}{l}0.68 \\
0.72\end{array}$ & $\begin{array}{l}0.72 \\
0.71\end{array}$ & $\begin{array}{l}\text { Case } 2 \\
\text { Case } 3\end{array}$ & $\begin{array}{l}180 \\
275\end{array}$ & $\begin{array}{l}335 \\
340\end{array}$ \\
\hline Mean & 0.68 & 0.72 & Mean & 175 & 285 \\
\hline
\end{tabular}

\begin{tabular}{|c|c|c|c|c|c|}
\hline \multicolumn{3}{|c|}{ End-diastolic volume $(\mathrm{ml})$} & \multicolumn{3}{|c|}{ Mean ejection rate $(\mathrm{ml} / \mathrm{sec})$} \\
\hline & Before & After & & Before & After \\
\hline Case I & 115 & 210 & Case I & 125 & 180 \\
\hline Case 2 & 190 & 300 & Case 2 & 120 & 170 \\
\hline Case 3 & 220 & 260 & Case 3 & 190 & 220 \\
\hline Mcan & 175 & 255 & Mean & 145 & 190 \\
\hline
\end{tabular}

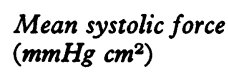

\begin{tabular}{|c|c|c|c|c|c|}
\hline & Before & After & & Before & After \\
\hline $\begin{array}{l}\text { Case I } \\
\text { Case } 2 \\
\text { Case } 3\end{array}$ & $\begin{array}{l}2200 \\
6300 \\
7500\end{array}$ & $\begin{array}{r}3900 \\
10500 \\
9000\end{array}$ & $\begin{array}{l}\text { Case I } \\
\text { Case } 2 \\
\text { Case } 3\end{array}$ & $\begin{array}{l}8 \cdot 3 \\
7 \cdot 1 \\
7 \cdot 6\end{array}$ & $\begin{array}{l}7 \cdot 1 \\
7 \cdot 1 \\
7 \cdot 8\end{array}$ \\
\hline Mean & 5200 & 7800 & & $7 \cdot 7$ & $7 \cdot 3$ \\
\hline
\end{tabular}

a sharp increase in cardiac output from 4.4 to 6.3 $1 . / \mathrm{min}(+43 \%)$, giving an increase in stroke volume from 54 to $72 \mathrm{ml}$ (Fig. 3). Measurements of ejection time were not consistently altered, but there was a tendency to an increase in the total duration of systole. In two subjects the thermodilution ratio (Table 3) was larger after glucagon so that the calculated end-diastolic volume, which is also affected by the change in stroke volume, was greatly increased, from 175 to $255 \mathrm{ml}$ ( $+46 \%$ ) (Fig. 4).

As a consequence of the increase in left ventricular volume and systolic pressure, there was a considerable increase in mean systolic force $(+50 \%)$. Prolongation of the total duration of systole and increase in heart rate further augmented the effect on forcetime per minute which increased by 6I per cent. The mean systolic ejection rate increased from 145 to $190 \mathrm{ml} / \mathrm{second}(+33 \%)$. Mean circumferential shortening rate fell considerably in one case, but there was little change in the other two as the effects of a larger ventricular volume were balanced by the greater stroke volume after glucagon (Fig. 5), and ejection time was little altered; the average change was from $7 \cdot 7$ to $7 \cdot 3 \mathrm{~cm} /$ second. 


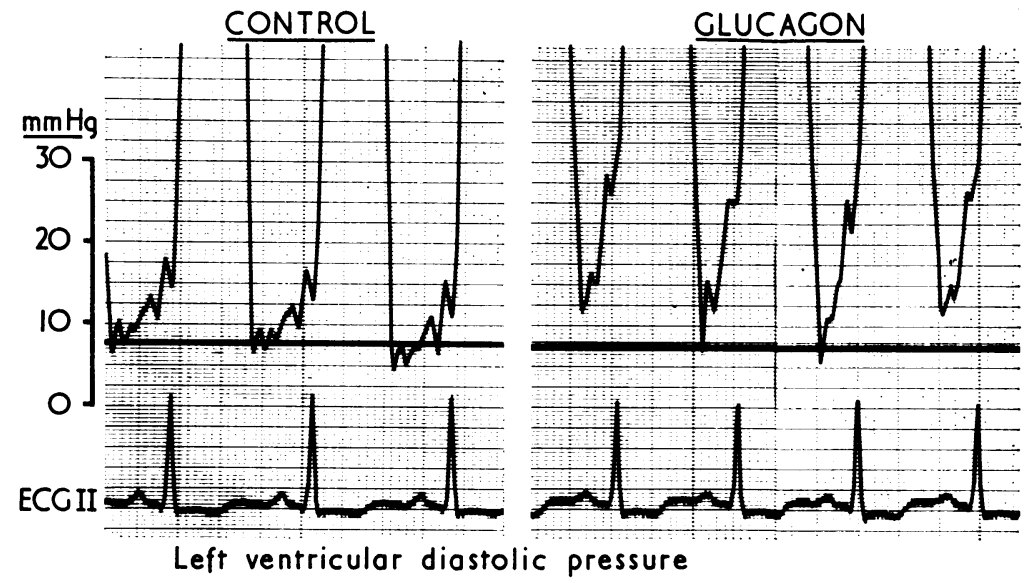

FIG. 2 Example of the effect of glucagon on left ventricular diastolic pressure (Case I).
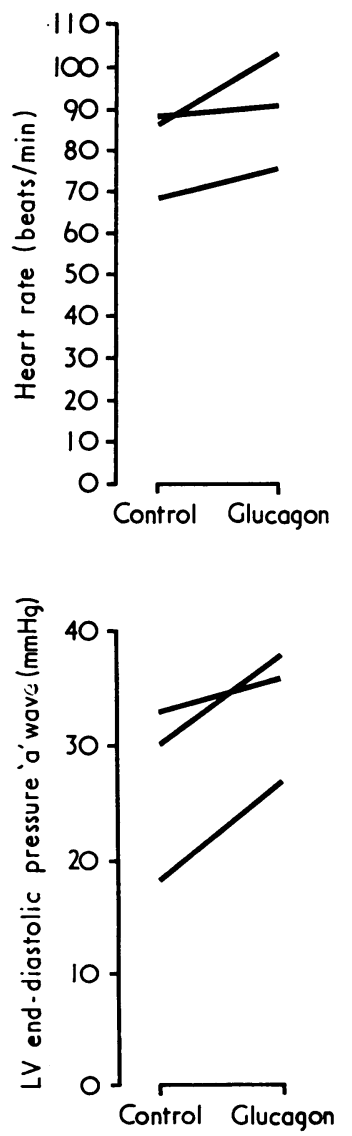
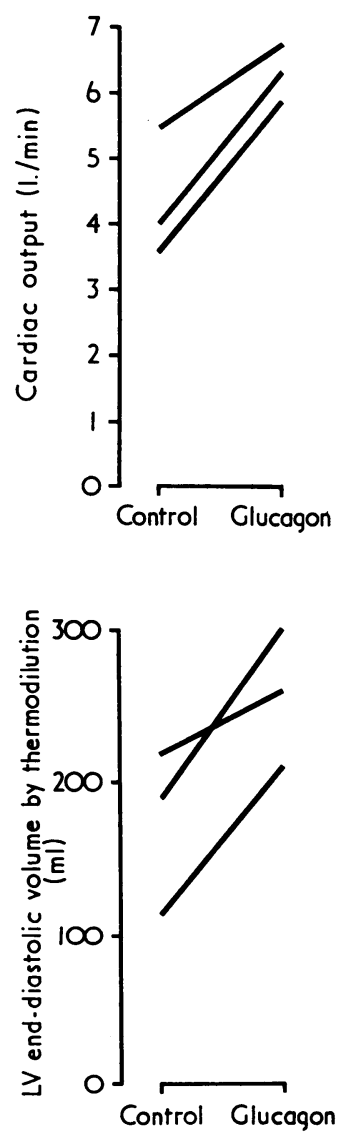

\section{Discussion}

Selection of patients with aortic stenosis for study

Though the main clinical use of glucagon in heart disease has been for cardiogenic shock or severe failure, patients with these conditions are difficult to study. Severe aortic stenosis presents a serious disturbance of left ventricular function requiring investigation for diagnostic purposes. Under these circumstances the addition of the assessment of the response to an intervention presents little additional difficulty. The present study is particularly appropriate in these patients as treatment with glucagon might be suggested should they develop severe left ventricular failure or a low output state after aortic valve replacement.
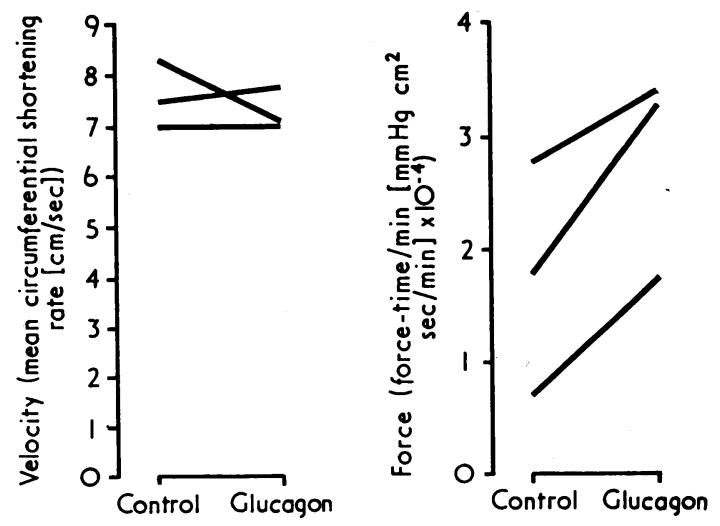

FIG. 3, 4, and 5 Haemodynamic effects of glucagon. Each bar represents the change in an individual patient. 
The thermodilution technique can be applied satisfactorily to patients with aortic stenosis. The method probably gives slight overestimates of the ventricular volumes as some indicator is lost to the ventricular wall, but the changes found between two observations still provide valid information. In general, valvar incompetence disturbs the volume measurements, but the aortic incompetence present in two of our cases will produce only a slight additional overestimate of left ventricular end-systolic volume (Hamer and Fleming, 1967).

An advantage from the point of view of analysis of peripheral and central effects of glucagon is the presence of a fixed obstruction in the left ventricular outflow tract so that the resistance to left ventricular ejection is effectively constant in severe aortic stenosis in spite of variations in peripheral arterial resistance. In the presence of severe aortic stenosis, left ventricular ejection follows a more uniform course than in a normal subject, and the error resulting from the assumption of an even emptying rate in calculation of force and velocity estimates is minimized.

\section{Indices of force and velocity of contraction}

The calculation of mean systolic force, as an index of the force developed in the left ventricular wall, is derived from the measurements of systolic pressure and ventricular volume. For an estimate of myocardial oxygen consumption the duration of systole must be included in the calculation; forcetime per minute is the most suitable index from this point of view. Mean systolic ejection rate gives some indication of the velocity of contraction, but is also influenced by the size of the chamber; mean circumferential shortening rate takes this aspect into consideration.

The relation of these measurements to the force and velocity of the individual muscle fibres depends on the effect of dilatation on the structure of the left ventricular wall. An acute change, without compensatory hypertrophy, will produce more effect on each fibre than suggested by the mean systolic force, in proportion to the reduction in thickness of the left ventricular wall. The physical characteristics of cardiac muscle (Leyton and Sonnenblick, 1969) make it unlikely that the fibres can stretch sufficiently to allow for more than slight dilatation of the ventricle. Any further enlargement of the chamber is due to rearrangement of the tissues of the ventricular wall with a corresponding reduction in the number of layers of fibres (Linzbach, 1960). These structural changes will have little effect on the force on each fibre, but are important in the assessment of velocity of contraction. Measurement of shortening rate in circumferences per second will give an underestimate of the behaviour of the individual fibres in proportion to the increase in the size of the chamber. Shortening rate expressed in $\mathrm{cm}$ per second provides a better indication of the velocity of contraction when there is slippage in the ventricular wall to accommodate an increase in volume.

In our patients with severe aortic stenosis the raised end-diastolic pressure is an indication of the stiffness of the hypertrophied left ventricle as well as increased stretching of the muscle fibres. As the length-tension curve of the sarcomeres rises steeply, the capacity for further stretch is limited, though a relatively small change may have an important functional effect through the Frank-Starling mechanism, and rearrangement of the fibres is probably the dominant mechanism allowing dilatation of the ventricle after glucagon. Changes in velocity of contraction were therefore assessed from the mean circumferential shortening rate expressed in $\mathrm{cm}$ per second, rather than in circumferences per second. Any error from this assumption will tend to overestimate the velocity of contraction as the ventricle dilates.

\section{Interpretation of the present findings}

Inotropic agents generally produce an increase in both the force and velocity of contraction, and a response of this type has been demonstrated after glucagon in animals (Glick et al., 1968). Arterial pressure and cardiac output rose and there was an increase in the rate of left ventricular ejection with only slight tachycardia. Similar effects have been reported at cardiac catheterization in man, but the response is modified by the underlying cardiac disease. Murtagh et al. (1970) found a 42 per cent increase in cardiac output in acute cardiac infarction, but only a 26 per cent increase after a similar dose in chronic rheumatic heart disease. The rate of rise of left ventricular pressure (dp/dt), a useful measure of the velocity of contraction, increased by 21 per cent.

The response of patients with low cardiac outputs seems to vary with the chronicity of the process. There have been several reports of considerable improvement in cardiogenic shock (Wilcken and Lvoff, 1970), especially after cardiac infarction (Mahon et al., 1968; Eddy, O'Brien, and Singh, 1969) or cardiopulmonary bypass (Linhart et al., 1968; Parmley et al., 1969). A response may be seen in chronic cardiac failure (Brogan et al., 1969), particularly in the presence of acute hypotension and a low cardiac output (Vander Ark and Reynolds, 1970), but in chronic rheumatic heart disease there seems to be little effect (Greenberg et al., 1970; Nord, Fontanes, and Williams, 1970). The lack of effect of glucagon noted clinically in chronic cardiac 
failure has been confirmed in isolated left ventricular papillary muscles from animals with experimental heart failure (Goldstein et al., 1971).

The findings in our patients with severe aortic stenosis suggest a great increase in the force of contraction and little change in velocity. An inotropic effect from glucagon might be expected to increase both force and velocity of contraction and the lack of detectable effect on velocity is difficult to explain, particularly as a reduction in velocity has been demonstrated with a negative inotropic agent by this method (Hamer and Fleming, 1967, 1969). In addition, a drug with positive inotropic activity would be expected to reduce left ventricular enddiastolic pressure and volume. It may be that the myocardium in our patients was relatively unresponsive to glucagon because of the long-standing left ventricular stress leading to failure, and that the increase in force of contraction was secondary to the increase in ventricular volume acting through the Frank-Starling mechanism. A large rise in enddiastolic volume followed the injection of glucagon in our patients in spite of the stiffness of the hypertrophied left ventricular walls. The corresponding increase in end-diastolic pressure (Fig. 6) suggests that there was some stretching of the individual fibres in spite of structural rearrangements in the ventricular wall. The increase in force (expressed as force-time per minute) was related to the increase in end-diastolic pressure (Fig. 7), and, as might be expected, there was a reciprocal relation between the changes in force and velocity of contraction (Fig. 8). The findings are consistent with a FrankStarling response in a ventricle that has increased in size, rather than any positive inotropic action of glucagon.

These changes might be taken to indicate a deterioration in left ventricular performance, but more probably are secondary to the increase in stroke volume resulting from the rise in cardiac output without concomitant change in heart rate. This added load would require a considerable increase in ventricular volume if the ejection fraction could not be increased. In the presence of severe outflow obstruction, a much greater wall force would be needed under these circumstances, and might be produced by the Frank-Starling mechanism with a relatively small increase in the end-diastolic length of the individual fibres of the hypertrophied left ventricle.

\section{Relevance to therapeutic use of glucagon}

Our choice of severe aortic stenosis for this study was dictated by the need for diagnostic left heart catheterization in these patients and by their suitability for the measurement of left ventricular
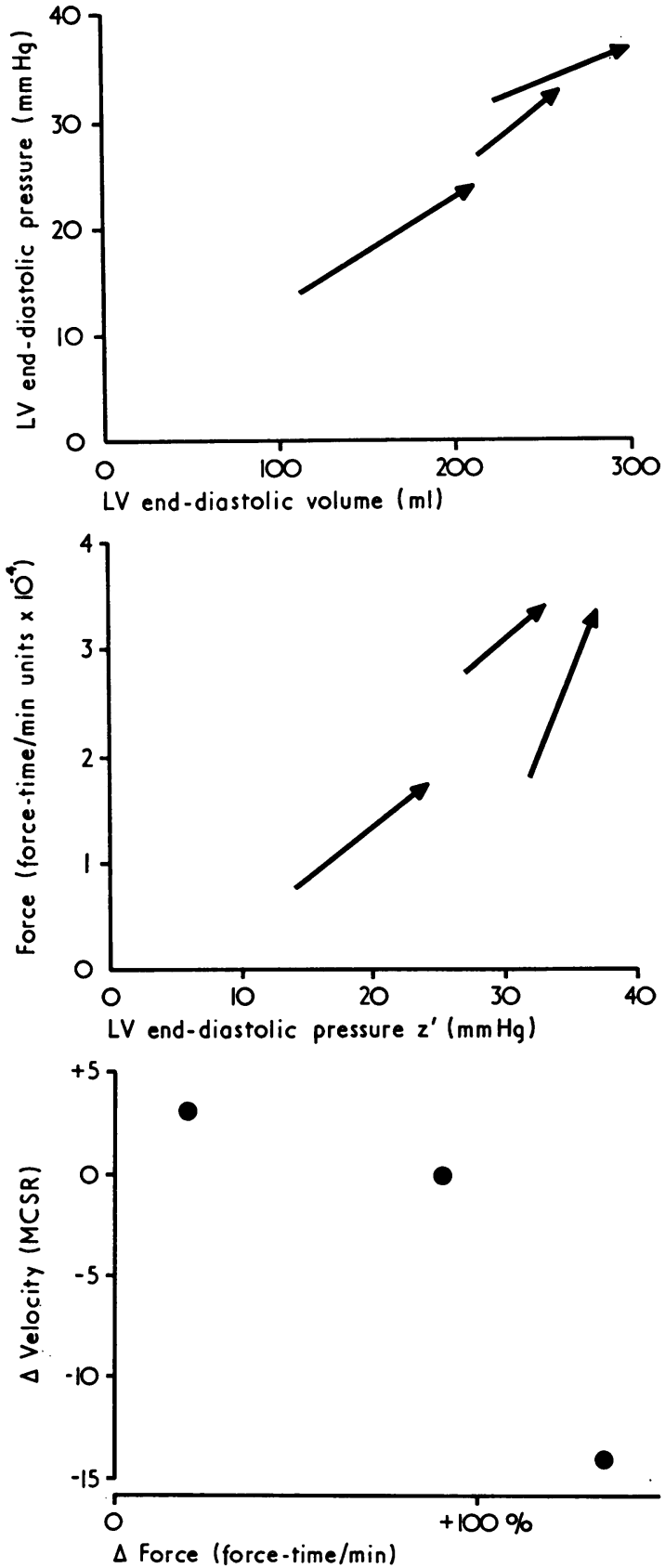

FIG. 6, 7, and 8 Effect of glucagon on left ventricular performance. Fig. 6 shows the corresponding increase in end-diastolic pressure and volume in each patient. Fig. 7 relates the increase in wall force to the rise in end-diastolic pressure. Fig. 8 compares the change in velocity with the change in force in each case; a greater effect on force is associated with a lesser effect on velocity. 
volume by the thermodilution technique. It could be argued that the long-standing left ventricular disease might have made these patients less responsive to glucagon than those patients with acute disorders such as cardiac infarction with shock. However, the raised left ventricular end-diastolic pressures in our patients are probably in the main a reflection of the increased stiffness of the very hypertrophied left ventricular wall, and the evidence of force generation suggests that the ventricles were still capable of a high level of performance. The severe outflow obstruction presented by aortic stenosis is a further major difference between our patients and the situation in cardiogenic shock where a low impedance to ejection would be expected. However, in both situations an increase in force in the effective muscle fibres in the left ventricular wall is required. It may be that the increase in cardiac output produced by glucagon could be managed by a normal heart without the increase in end-diastolic pressure and volume observed in our patients, but it seems likely that a similar response would have been observed in patients with other types of left ventricular disease. The increase in force-time per minute in our patients after glucagon suggests a corresponding rise in myocardial oxygen consumption which might put an undue demand on a limited coronary circulation. Relative myocardial ischaemia produced in this way may limit the response to glucagon in patients with coronary artery disease, or in ventricular hypertrophy where the relations between the muscle fibres and the capillary bed may be distorted.

An increase in cardiac output has frequently been observed after glucagon, and is usually attributed to the inotropic effect on the heart, but it seems unlikely that an effect of glucagon on left ventricular performance can have been responsible for the considerable rise in cardiac output observed here. It has been suggested (J. McMichael, I97I, personal communication) that the response of the relatively unstressed right ventricle to glucagon could have been the cause of the increase in cardiac output. Unfortunately, our experimental design did not allow us to study right ventricular behaviour to assess this possibility. However, there is other evidence pointing to a possible peripheral factor. The increase in pulse pressure without any noticeable change in mean pressure in the aorta is much against any general peripheral vasodilatation, but there is evidence that glucagon can produce very great local increases in blood flow, particularly in the splanchnic circulation. The distribution of the regional vasodilatation produced by glucagon has been investigated in animals. Ross (1970), using external cuff electromagnetic flow meters on the femoral, hepatic, superior mesenteric, and renal arteries, found that the vasodilatation was confined to the splanchnic area in the cat. Katz and Mills (197I), with a catheter tip velocity probe in the dog, found more widespread vasodilatation, affecting aortic, mesenteric, and renal flow particularly, though carotid and femoral flow were increased by larger doses. A dose of $25 \mu \mathrm{g} / \mathrm{kg}$ increased mesenteric flow velocity to nearly three times the control value from I to 5 minutes after the intravenous injection. Similar changes in the splanchnic circulation in man might produce the observed effects on cardiac output without necessarily affecting the mean aortic pressure if there were compensating adjustments in other vascular beds. Such a redistribution of regional blood flow would reduce any benefit in terms of renal, cerebral, and myocardial perfusion that might be expected from an increase in cardiac output in cardiac failure or cardiogenic shock. In view of these considerations, and the lack of inotropic response of the myocardium to glucagon in heart failure, the therapeutic value of glucagon seems to be considerably limited.

Though our patients experienced no ill effects other than nausea after glucagon was given, and there was no noticeable increase in breathlessness or fall in aortic pressure, the sharp increase in enddiastolic pressure and volume in the left ventricle which we observed in each case made us unwilling to continue this investigation. In addition, recent evidence has suggested that intravenous injection of glucagon might produce small emboli of hyaline material in the lungs (Sheddon, 1971), though the relevance of this animal work to the use of glucagon in man has been questioned (Condon, Knight, and Day, 1972). However, as our three patients showed similar responses, we feel that valid conclusions can be drawn from the limited information we have obtained.

\section{References}

Brogan, E., Kozonis, M. C., and Overy, D. C. (1969). Glucagon therapy in heart failure. Lancet, 1,482 .

Condon, J. R., Knight, M. J., and Day, J. (1972). Intravenous glucagon. British Medical fournal, $\mathrm{r}, 376$.

Eddy, J. D., O'Brien, E. T., and Singh, S. P. (1969). Glucagon and haemodynamics of acute myocardial infarction. British Medical fournal, 4, 663.

Glick, G., Parmley, W. W., Wechsler, A. S., and Sonnenblick, E. H. (1968). Glucagon: its enhancement of cardiac performance in the cat and dog and persistence of its inotropic action despite beta-receptor blockade with propranolol. Circulation Research, 22, 789.

Goldstein, R. E., Skelton, C. L., Levey, G. S., Glancy, D. L., Beiser, G. D., and Epstein, S. E. (1971). Effects of chronic heart failure on the capacity of glucagon to enhance contractility and adenyl cyclase activity of human papillary muscles. Circulation, 44, 638. 
Greenberg, B. H., Tsakiris, A. G., Moffitt, E. A., and Frye, R. L. (1970). The haemodynamic and metabolic effects of glucagon in patients with chronic valvular heart disease. Mayo Clinic Proceedings, 45, 132.

Hamer, J., and Fleming, J. (I967). Effect of propranolol on left ventricular work in aortic stenosis. British Heart fournal, 29, 87 I.

Hamer, J., and Fleming, J. (1969). Action of propranolol on left ventricular contraction in aortic stenosis when a fall in heart rate is prevented by atropine. British Heart fournal, 31, 670.

Katz, R. L., Hinds, L., and Mills, C. J. (1969). Ability of glucagon to produce cardiac stimulation without arrhythmias in halothane-anaesthetized animals. British fournal of Anaesthesia, 41, 574.

Katz, R. L., and Mills, C. J. (1971). Use of a catheter tip electromagnetic velocity meter to determine the cardiovascular effects of glucagon. Cardiovascular Research, 5, 62 .

Leyton, R. A., and Sonnenblick, E. H. (1969). The ultrastructure of the failing heart. American fournal of the Medical Sciences, 258, 304.

Linhart, J. W., Barold, S. S., Cohen, L. S., Hildner, F. J., and Samet, P. (1968). Cardiovascular effects of glucagon in man. American fournal of Cardiology, 22, 706.

Linzbach, A. J. (1960). Heart failure from the point of view of quantitative anatomy. American fournal of Cardiology, 5, 370.

Mahon, W. A., Morch, J. E., and Klein, S. W. (1968). Cardiovascular effects of intravenous glucagon in man (abstract). Circulation, 38, Suppl. 6, 132.

Murtagh, J. G., Binnion, P. F., Lal, S., Hutchison, K. J., and
Fletcher, E. (1970). Haemodynamic effects of glucagon. British Heart fournal, 32, 307.

Nord, H. J., Fontanes, A. L., and Williams, J. F. (1970). Treatment of congestive heart failure with glucagon. Annals of Internal Medicine, 72, 649.

Parmley, W. W., Matloff, J. M., and Sonnenblick, E. H. (1969). Haemodynamic effects of glucagon in patients following prosthetic valve replacement. Circulation, 39, Suppl. I, I63.

Ross, G. (1970). Regional circulatory effects of pancreatic glucagon. British fournal of Pharmacology, 38, 735.

Sarnoff, S. J., Braunwald, E., Welch, G. H., Case, R. B., Stainsby, W. N., and Macruz, R. (1958). Haemodynamic determinants of oxygen consumption of the heart with special reference to the tension-time index. American fournal of Physiology, 192, 148.

Sheddon, W. I. H. (I97I). Intravenous glucagon. British Medical fournal, 4, 815.

Shinebourne, E., Fleming, J., and Hamer, J. (1967). Calibration of indicator dilution curves in man by the dynamic method. British Heart fournal, 29, 920.

Vander Ark, C. R., and Reynolds, E. W. (1970). Clinical evaluation of glucagon by continuous infusion in the treatment of low cardiac output states. American Heart fournal, 79, 481 .

Wilcken, D. E. L., and Lvoff, R. (1970). Glucagon in resistant heart-failure and cardiogenic shock. Lancet, I, 1315.

Requests for reprints to Dr. John Hamer, Department of Cardiology, St. Bartholomew's Hospital, London E.C.I. 